\title{
We Call for iCAALL: International Collaboration in Asthma, Allergy and Immunology
}

\author{
Jan Lötvall, MD, PhD, ${ }^{1}$ Ruby Pawankar, MD, PhD, ${ }^{2}$ Dana V. Wallace, MD, ${ }^{3}$ Cezmi A. Akdis, MD, ${ }^{4}$ \\ Lanny J. Rosenwasser, MD, ${ }^{5}$ Richard W. Weber, MD, ${ }^{6}$ A. Wesley Burks, MD, ${ }^{7}$ Thomas B. Casale, MD, ${ }^{8}$ \\ Richard F. Lockey, MD, ${ }^{9}$ Nikolaos Papadopoulus, MD, PhD, ${ }^{10}$ Stanley M. Fineman, MD, ${ }^{11}$ \\ and Dennis K. Ledford, MD, ${ }^{12}$ on behalf of the American Academy of Allergy, Asthma \& Immunology \\ (AAAAI), the American College of Allergy, Asthma \& Immunology (ACAAI), the European Academy of \\ Allergy and Clinical Immunology (EAACI), and the World Allergy Organization (WAO)* Göteborg, \\ Sweden, Tampa and Ft. Lauderdale, Florida, Tokyo, Japan, Davos, Switzerland, Kansas City, Missouri, \\ Denver, Colorado, Chapel Hill, North Carolina, Omaha, Nebraska, Athens, Greece, and Atlanta, Georgia
}

From the ${ }^{1}$ Krefting Research Centre, University of Gothenburg, Göteborg, Sweden; ${ }^{2}$ Nippon Medical School, Yayoi, Tokyo, Japan; ${ }^{3}$ Nova Southeastern University, Ft. Lauderdale, FL; ${ }^{4}$ the Swiss Institute of Allergy and Asthma Research (SIAF), University of Zurich, Davos; ${ }^{5}$ Children's Mercy Hospital, Kansas City, MO; ${ }^{6}$ National Jewish Health, Denver, CO; ${ }^{7}$ Department of Pediatrics, University of North Carolina, Chapel Hill, NC; ${ }^{8}$ Creighton University, Omaha, NE; ${ }^{9}$ Division of Allergy/Immunology, University of South Florida, Tampa, FL; ${ }^{10}$ Allergy Department, $2^{\text {nd }}$ Pediatric Clinic, University of Athens; ${ }^{11}$ Department of Pediatrics, Emory University School of Medicine, Atlanta, GA; and ${ }^{12}$ Division of Allergy/ Immunology, University of South Florida, Tampa, FL.

*Society representatives: AAAAI: A.W. Burks, T.B. Casale, D.K. Ledford; ACAAI: D.V. Wallace, R.W. Weber, S.M. Fineman; EAACI: J. Lötvall, C.A. Akdis, N.G. Papadopoulos; WAO: R. Pawankar, L.J. Rosenwasser, R.F. Lockey.

This editorial is being co-published by Allergy, the Annals of Allergy, Asthma, \& Immunology, the Journal of Allergy and Clinical Immunology, and the World Allergy Organization Journal.

Disclosure of potential conflict of interest: J Lötvall has consulted for GlaxoSmithKline, Novartis, and Merck; has received grants from GlaxoSmithKline; and has received payment for lectures from AstraZeneca, GlaxoSmithKline, Novartis, and Merck. CA Akdis has received research support from Novartis, the Swiss National Science Foundation, the European Commission, the Global Allergy and Asthma European Network, and the Christine Kühne Center for Allergy Research and Education (for which he is the director); he has also consulted for Actellion, Aventis, Stallergenes, and Allergopharma. LJ Rosenwasser has consulted for Sanofi, Regeneron, Novartis, Genentech/ Roche, and AstraZeneca; has received grants from the National Institutes of Health $(\mathrm{NIH})$ and Novartis; and has received payment for lectures from Genentech, Roche, AstraZeneca, and Alcon; in addition, he holds patents related to IL-1. RW Weber has received grants from Genentech, Novartis, and Merck, and has received payment for lectures from Genentech and AstraZeneca. AW Burks has consulted for Dannon Co. Probiotics, Exploramed Development LLC, Intelliject, McNeil Nutritionals, Merck \& Co., Novartis, Nutricia, Pfizer, Portola Pharmaceuticals, and Schering-Plough; has received grants from the Food Allergy and Anaphylaxis Network, the Food Allergy Initiative, the NIH, the National Peanut Board, SHS, and the Wallace Research Foundation; and owns stock or stock options in Allertein and Mast Cell, Inc. RF Lockey has consulted for Merck and ALK; has received grants from the $\mathrm{NIH}$ and the VA; has received payment for lectures from Merck and AstraZeneca; and has received royalties from Informa. N Papadopoulos has served on an advisory board for Abbott; has received grants from Nestlé, MSD, and Deviblis (EBT); has received payment for lectures from Allergopharma, Uriach, and GlaxoSmithKline; and has received payment for development of educational presentations from MSD and Uriach. The other authors declare that they have no relevant conflicts.

Correspondence to: Ruby Pawankar, MD, PhD, Nippon Medical School, 4F Ichigokan, 1-4-10, Yayoi, Bunkyo-ku, Tokyo, Japan. E-mail: pawankar. ruby@gmail.com.

Copyright (c) 2012 by World Allergy Organization
The incidence of allergic diseases and asthma is increasing throughout the world, and therefore these diseases pose major medical and socioeconomic problems globally. ${ }^{1,2}$ This is particularly true in the developed world, which has experienced a tremendous increase in the prevalence of allergic diseases and asthma over the last 50 years. ${ }^{2,3,4,5}$ Asthma currently affects $8 \%$ to $12 \%$ of the population in the developed world, and the prevalence of allergic rhinitis continues to increase and currently affects approximately $20 \%$ to $25 \%$ of this same population. ${ }^{6,7}$ Patients affected by these allergic disease states are recognized to have a poorer quality of life, reduced work productivity and school attendance, comorbidities, and increased health care costs. ${ }^{2}$

The reasons for the negative effects of allergies and asthma are variable, but in most countries patients with these diseases are either inadequately or improperly treated, resulting in a greater negative effect and resources expended. The awareness of these trends among politicians, other policymakers, patients, the general public, and many health care insurers outside the specialty of allergy and immunology is limited. This lack of awareness and knowledge gap has resulted in reduced resources allocated to treat and promote research for these diseases.

Over the past 2 decades, the population of the world has increased from approximately 5.3 to 7 billion, and by the year 2050 , it is estimated to reach 9 to 10 billion. As rapid population growth occurs, people are more likely to live in urban environments. In fact, some estimates predict that $60 \%$ to $70 \%$ of the world's population will live in cities and their surrounding areas by 2050 . Because urbanization results in lifestyle changes and an increased exposure to environmental pollutants, an even further increase in the prevalence of allergic diseases and asthma is expected worldwide.

This is illustrated by the fact that allergic diseases and asthma increase in parallel to urbanization. ${ }^{8}$ Some futurists estimate that the prevalence of asthma will affect $10 \%$, or approximately 1 billion, of the world's population by 2050 . This increase will not only affect the collective quality of life of these populations but also negatively affect their economies. Likewise, several billion persons will have other 
allergic diseases, such as allergic rhinitis, with a concomitant increased incidence of comorbidities.

To address these concerns and prepare for the resulting needs worldwide, the American Academy of Allergy, Asthma \& Immunology; the American College of Allergy, Asthma \& Immunology; the European Academy of Allergy and Clinical Immunology; and the World Allergy Organization have formed a collaborative outreach program termed the International Collaboration in Asthma, Allergy and Immunology (iCAALL). The mission of iCAALL will be to increase and coordinate the communication of information about allergies, asthma, and immunologic diseases on a global level. It will develop communications tools for specialists, general practitioners, and other health care professionals and, ultimately, provide information for the general public, patients, and policymakers around the world. Hopefully, this consorted effort will result in a greater awareness about allergies, asthma, and immunologic diseases, resulting in more competent care for patients by health care professionals and increased allocation of resources for research and patient care, thus benefitting these patients and societies as a whole.

The first project underway is for iCAALL to produce international consensus statements (ICONs) to serve as important resources for physicians and other health care professionals who care for and manage patients with allergic and immunologic diseases. ICONs will also serve to educate policymakers about the need to provide access to care and resource allocation to ensure optimal patient care. Two ICONs on eosinophilic diseases and pediatric asthma are currently under development, and a third on food allergy has recently been published. ${ }^{9}$ Additional ICONs will be developed in future years. These concise documents will be authored by a multinational group of experts who will review the pertinent literature and summarize the salient points of various allergic diseases, including their pathogenesis, clinical characteristics, and treatment.

iCAALL will also promote awareness, collaboration, and international recognition of allergy, asthma, and immunologic diseases. This will include the development of consensus documents and possibly guidelines for the diagnosis and treatment of various allergic and immunologic diseases and asthma. The developmental process will involve a large group of worldwide specialists; other health care professionals, including primary care physicians; and the patients we serve and will use both traditional and newer Internet-based interactive techniques for sharing data and opinions. The ICONs will combine the best scientific evidence with expert consensus and will be adaptable for all countries worldwide, allowing for modifications based on the availability of regional diagnostic and therapeutic interventions. Using this new approach, iCAALL is optimistic that it will be possible to achieve universal acceptance of the evolving consensus documents by the health care community, thereby helping to create a bridge between specialists and primary care physicians: the world will have a more pragmatic approach to the diagnosis and treatment of these common diseases.

\section{REFERENCES}

1. Schoenwetter WF, Dupclay L Jr, Appajosyula S, Botteman MF, Pashos CL. Economic impact and quality-of-life burden of allergic rhinitis. Curr Med Res Opin. 2004;20:305-317.

2. Pawankar R, Canonica GW, Holgate ST, Lockey RF, eds. WAO White Book on Allergy. Milwaukee, WI: World Allergy Organization; 2011:1-216.

3. Pearce N, Aït-Khaled N, Beasley R, Mallol J, Keil U, Mitchell E, Robertson C. Worldwide trends in the prevalence of asthma symptoms: phase III of the International Study of Asthma and Allergies in Childhood (ISAAC). Thorax. 2007;62:758-766.

4. Varjonen E, Kalimo K, Lammintausta K, Terho P. Prevalence of atopic disorders among adolescents in Turku, Finland. Allergy. 1992;47:243-248.

5. Rönmark E, Perzanowski M, Platts-Mills T, Lundbäck B. Incidence rates and risk factors for asthma among school children: a 2-year follow-up report from the obstructive lung disease in Northern Sweden (OLIN) studies. Respir Med. 2002;96:1006-1013.

6. Lötvall J, Ekerljung L, Rönmark EP, Wennergren G, Lindén A, et al. West Sweden Asthma Study: prevalence trends over the last 18 years argues no recent increase in asthma. Respir Res. 2009;10:94.

7. Settipane RA, Charnock DR. Epidemiology of rhinitis: allergic and nonallergic. Clin Allergy Immunol. 2007;19:23-34.

8. Robinson CL, Baumann LM, Romero K, Combe JM, Gomez A, et al. Effect of urbanisation on asthma, allergy and airways inflammation in a developing country setting. Thorax. 2011;66:1051-1057.

9. Burks AW, Tang M, Sicherer S, Muraro A, Eigenmann PA, Ebisawa M, et al. ICON: food allergy. J Allergy Clin Immunol. 2012; published online ahead of print, 24 February 2012. doi:10.1016/j.jaci.2012.02.001. 